\title{
Paramedic-conducted Mental Health Counselling for Abused Women in Rural Bangladesh:An Evaluation from the Perspective of Participants
}

\author{
Ruchira T. Naved', Nadia A. Rimi', Shamshad Jahan', and Gunilla Lindmark² \\ 'ICDDR,B, GPO Box 128, Dhaka 1000, Bangladesh and 'International Maternal and Child Health, \\ Uppsala University, Uppsala, Sweden
}

\begin{abstract}
This paper reports on evaluation of an initiative to use paramedics as the first-level mental health counsellors of abused women in rural Bangladesh (2003-2004) from the perspective of the abused women who participated in one or more counselling sessions. Thirty in-depth interviews, followed by a survey $(n=372)$, targeted to cover all participants, were conducted in 2006. Overall, the arrangement, management of ethical issues, and skills of paramedics were rated favourably. Most (89\%) abused women $(n=372)$ considered the session useful; one-fourth of these women considered it very useful; and only a few abused women considered the session useless. Usefulness of the session was expressed mostly in terms of relief attained after talking about the issue. Most (87\%) women reported being encouraged to be self-confident. In a context characterized by low self-confidence of women, lack of opportunity to talk about violence, and absence of professional mental health counselling services, this initiative is sufficiently promising to warrant further testing.
\end{abstract}

Key words: Battered women; Counselling; Mental health; Paramedics; Bangaldesh

\section{INTRODUCTION}

Nowhere in the world is gender imbalance more present than South Asia. Violence against women is a pervasive problem in this region (1). In addition to physical violence, South Asia documented the highest rates of sexual and emotional violence against women.

A population-based study conducted in 2001 in Bangladesh by ICDDR,B and Naripokkho-a women's activist organization - as part of a World Health Organization (WHO) multi-country study on violence against women (VAW) found that two in every five women had been physically abused by their husbands in both rural and urban areas of Bangladesh (2). Sexual violence within marriage was even higher in rural Bangladesh with every second woman reporting sexual abuse by her husband (3). Emotional violence by a husband was reported by $44 \%$

Correspondence and reprint requests should be addressed to:

Dr. Ruchira Tabassum Naved

Public Health Sciences Division

ICDDR,B

GPO Box 128, Dhaka 1000

Bangladesh

Email: ruchira@icddrb.org of urban women and $31 \%$ of rural women (3).

Evidence on negative consequences of physical and sexual violence on mental health of women is abundant in literature. Results of studies in North America showed that depression and post-traumatic stress disorder, which have substantial comorbidity, are the most prevalent mental health sequelae of intimate partner violence (4-11).

The developed world generate most literature on consequences of violence against women. A few studies conducted in developing countries on this issue basically substantiate the findings from developed countries. For example, 70\% of emotional distress cases in Nicaragua was attributed to intimate partner violence (12), and $72 \%$ of physically-abused women in Pakistan were suffering from depression and anxiety (13). In Bangladesh, results of the ICDDR,B-Naripokkho study suggest an association between physical violence by husbands and mental health problems in women ranging from functional disorders to suicidal intention (14) and attempted suicide (3). Moreover, it indicates a dose effect of the frequency and severity of physical abuse on the level of emotional distress of women.

The majority (66\%) of urban and rural women 
in Bangladesh never discussed their experience of spousal violence with anyone (2). Sixty percent of urban and $51 \%$ of rural abused women never received any help in addressing violence. Only $2 \%$ ever sought help from institutional sources, from where support was not forthcoming.

Although mental health counselling services are effective in increasing the efficacy of abused women, strengthening the coping skills of women, and enhancing their decision-making ability in other settings (15-20), so far mental health of abused women has remained an area inadequately addressed by any policy or programme in Bangladesh. Counselling expertise in the area of domestic violence has only begun to be developed in Bangladesh, and currently, only a few mental health counsellors in the country have been trained in counselling of abused women. These counsellors are mostly citybased. Even the government initiative to provide some mental health services to abused women through One Stop Crisis Centres are based in divisional hospitals only. Thus, a huge imbalance exists between the available supply and the need throughout the country, particularly in rural areas. Given the resource constraints making available, a team of professional counsellors providing services to abused women throughout Bangladesh does not seem to be practical.

In this scenario, in 2001, ICDDR,B became part of an initiative for developing a group of counsellors for providing service to abused women in Bangladesh. Counselling was provided to abused women as part of a larger study known as Maternal and Infant Nutrition Interventions in Matlab (MINIMat). The MINIMat study enrolled all pregnant women in Matlab from 2001 to 2003. The questionnaire on violence was administered at the clinic-visit during 30th week of gestation. A modified version of conflict tactic scale (CTS) was used for exploring exposure of women to violence (21). The self-reporting questionnaire with 20 items (SRQ-20) developed by the World Health Organization was used for measuring mental stress. The possible answers were on a yes/no basis. For a 'yes' response, the respondent was given a score of 1 and for a 'no' response the score given was 0 . Thus, the range of scores on the SRQ-20 varied from 0 to 20 , with 0 representing no mental health problems and 20 representing severe problems.

The MINIMat trained ICDDR,B's paramedics based in Matlab-a rural area-in mental health counselling for abused women. A six-day training, followed by two sessions of refresher training of paramedics, was conducted. A mental health counselling team initiated by Naripokkho-ICDDR,B trained the female paramedics. One of the trainers had a PhD in psychology, five had master's degree in clinical psychology, and two had master's degree in psychology. All the trainers had special training in mental health counselling of abused women and experience in conducting counselling sessions.

The paramedics trained in counselling had a minimum grade 12 education and 18 months of training as Family Welfare Visitors. Their work experience ranged from 8 to 29 years. The usual responsibility of the paramedics at ICDDR,B included management of outpatient department (OPD), emergency care, delivery, antenatal care, postnatal care, and ultrasonography in four ICDDR,B clinics. In total, eight paramedics were trained. The four paramedics who ranked best during the training started conducting the session. A fifth one was assigned this responsibility when one of the paramedics providing counselling left ICDDR,B.

The training focused on gender-based violence against women, its root causes and determinants, psychosocial consequences of this violence, basics of counselling, and how to help abused women to manage stress, improve coping, and enhance well-being following the framework developed by Romano (22). This framework includes three components: (a) increasing awareness of behaviours and reactions associated with a stressful situation, (b) improving coping strategies, and (c) strengthening well-being. Increasing awareness of personal responses to stressful situations, such as violent behaviour, is important. Stress reactions largely depend on appraisal of a situation (23-24), and a discussion of the role of private thoughts in stress reactions is essential as people usually understand from discussion of their own experience how thinking behaviours influence their emotions.

Analyses of thoughts surrounding stressful situations help in more accurate appraisals of stress (25) and facilitate an awareness of irrational and distorted thoughts (e.g. blaming self for being abused) and that can contribute to stress reactions. Clients need to be helped in changing, improving, or strengthening their coping strategies to better manage a stressful situation. The main emphasis in such counselling is given to cognitive change in the form of cognitive restructuring, in which clients are facilitated to replace irrational and distorted beliefs and thoughts with self-statements that are more ra- 
tional and realistic and change self-defeating and stress-producing thoughts to those that are more self-enhancing and reduce stress reactions. The final component of this model encourages clients' behaviours and strategies to enhance their overall well-being to buffer the effects of future stressors and life changes.

To the extent possible, the following guidelines for feminist therapy were followed in implementing the framework described above: (a) exploring the prescribed roles for women in society and contradictions within the context of the woman's story. For example, in Bangladeshi families, a husband is generally supposed to be the income-earner, and a wife is supposed to perform household chores. Even if the husband fails to bring home food, he may beat his wife for not having a meal ready. Following the feminist theory, these explorations of contradictions are expected to help validate the experience of the woman and shift the responsibility from the victim to the perpetrator (26); (b) making the session a shared inquiry between paramedic and client, where the paramedic uses a participatory approach based on an equal relationship (27-29); and (c) recognizing the importance of empowerment of the woman following feminist therapists (29-30) and defining it as a process whereby the woman was encouraged to make her own decision, honour her own feelings, and choose her own action. Women were given opportunities to explore their inherent coping abilities and capacity for self-healing. As Yam notes that it is important to view the woman as a person who can make decisions and collaborate with others to solve her problem, allowing the woman to express her feelings to a nonjudgemental and empathetic person and make her own decisions about the future (31).

Mental health counselling was provided to women reporting physical or sexual violence or suicidal ideation or attempt. Counselling service was offered during March 2004-June 2005, and women who agreed to come for the first session were assigned an appointment. All the women who attended the counselling session did so at least several months after the delivery.

Women who reported both physical and sexual violence and suicidal ideation or attempt during the interview were invited first for an individual counselling session. Once this list of women was exhausted, women exposed to only one of the forms of violence and suicidal ideation were invited for the session. Women exposed to any one of the forms of violence but not reporting any suicidal behaviour, i.e. suicidal ideation or attempt, were invited to the session at the final stage. Counselling service was offered and provided until the funds for providing such service were exhausted. ICDDR,B arranged transport for bringing women from home to the subcentres for the first session. In total, 416 women were contacted, and 410 women attended the first session. The paramedics were instructed to request the women to contact the Community Health Research Workers of ICDDR,B to make an appointment for a consecutive session. No transport was provided or conveyance was paid for consecutive sessions. Refreshments were arranged in all the sessions. In total, 402 women attended one session; nine women came for a second session; two women came for a third session; and one woman came for the fourth session.

The counselling service was provided once a week at four ICDDR,B local clinics in Matlab known as subcentres. A maximum of three counselling sessions were conducted per day. Counselling was provided under close supervision of a trained mental health counsellor having a master's degree in psychology. For the first six months, debriefing sessions were conducted at the end of each counselling day. Challenges in providing counselling and possible ways of overcoming these were discussed with the paramedics. Weekly group meetings were held with paramedics for sharing of experience and guidance by the supervisor. A counselling expert and academician with long experience in conducting counselling sessions for abused women worked as an advisor to the project. The supervisor regularly consulted the advisor. The advisor conducted several discussion meetings with the whole team.

This study evaluated this service through follow-up of women who availed of it. Specific objectives of the study included assessment of: (a) organizational aspects of the session, such as timing, waiting time, and the length of the session; (b) ethical guidelines followed in the intervention, such as maintenance of privacy and confidentiality; and (c) paramedic performance, measured by attitude and behaviour, ability to understand participant's narratives, encouragement for exploring a way out of violence; (d) usefulness of the service; and (e) determinants of usefulness of such service for abused women.

\section{MATERIALS AND METHODS}

Both qualitative and quantitative research methods 
were used in evaluating the intervention from the perspective of the abused women attending the session(s). In measuring the quality of care of different aspects of service provided at the pre-arrival and arrival stages, the interaction with the provider and the outcomes of the service were taken into account. Although transport was arranged for attending the first counselling session, there were likely many remaining obstacles to participating in the programme, such as inconvenient days and hours, indirect costs, workload, and restrictions on mobility. In the evaluation, the women were asked about barriers to attending the session.

Literature shows that both waiting-time and duration of session affect satisfaction with the service (32). For this reason, waiting-time, the total duration of the session, and how these were perceived by women were included in the assessment of quality of service. Since maintainance of ethical standards in delivering services concerning such a sensitive issue as violence was of utmost importance, special attention was paid in the evaluation to maintenance of confidentiality and privacy. The performance of the paramedics was measured by their attitude towards the women, non-judgemental nature of their interaction, equal treatment, and ability to understand the woman's story and situation.

For long-term counselling care, the final outcome criteria and evaluation might centre on ending abuse. For relatively short-term care criteria for successful outcome would be making the victim recognize that she is not to be blamed for violence, making her aware of her strengths and coping skills, and helping her to establish or re-establish social networks. In the case of the current programme, the overwhelming majority (97\%) of the clients attended only one session. So, it can be assumed that not all these indicators for short-term care would be appropriate for measuring the success of the current intervention. Thus, the final outcome of the session was measured in terms of satisfaction of the participants with different aspects of the session and a global evaluation of its usefulness and also in terms of reasons for not coming for a second session.

Both qualitative and quantitative research methods were used for evaluating the service. In-depth interviews to assess the service were carried out with 30 participants in counselling session during August 2006. Purposive sampling method was used for selecting the women for in-depth interviews. As there were funding constraints and the number of women who would participate in the programme was unknown, women residing closest to the ICDDR,B hospital were approached first, and then women living farther were approached as long as the funds allowed. Trained female interviewers with master's degree in anthropology and sociology conducted the interviews. Consent was sought for tape-recording the interview. The interviewers transcribed the data. A code list was prepared based on a list of general themes, which was modified in the process of coding for allowing new understanding and subthemes to emerge from the analysis of transcripts. Two data collectors coded data using the Atlas/ti software. The data were retrieved by codes, and search was performed for patterns and ideas for explaining those patterns in the data.

In-depth interviews were followed up by a survey conducted during June-August 2007. In-depth interviews were conducted for achieving a detailed understanding of how the abused women assessed the intervention. Data from these in-depth interviews helped develop the questionnaire for the survey. The qualitative data were also useful in formulating the questions in an appropriate language using appropriate terms. They helped interpret the quantitative results as well. The survey was conducted to assess the intervention that is generalizable across programme participants. It was intended to include all the women who attended the sessions. The final sample obtained for the survey was 372 (Table 1). The women lost to follow-up were mainly due to migration or long-term absence from households. Background characteristics of the women lost to follow-up were not differerent from the women covered by the survey. As shown by MINIMat data, they also did not differ from the obtained sample in terms of exposure to physical and/or sexual violence.

\begin{tabular}{|lc|}
\hline \multicolumn{2}{|l|}{ Table 1. Distribution of target sample $(\mathrm{n}=410)$} \\
\hline $\begin{array}{l}\text { Status of target sample in } \\
\text { terms of coverage }\end{array}$ & Percentage \\
\hline $\begin{array}{l}\text { Not found } \\
\text { Household was not found }\end{array}$ & 0.5 \\
$\quad \begin{array}{l}\text { Absence from household for a } \\
\text { long time }\end{array}$ & 7.1 \\
$\quad \begin{array}{l}\text { There was nobody in the } \\
\text { household }\end{array}$ & 1.2 \\
$\begin{array}{l}\text { Dead/deaf } \\
\text { All completed }\end{array}$ & 0.5 \\
Total & 90.7 \\
\hline
\end{tabular}


Careful attention was given to a number of ethical concerns in this study. Consent from women was sought at the end of the counselling session for going back to them, which allowed this evaluation to take place. Standard informed consent procedures were followed before the in-depth and survey interviews. At the start of all interviews, the participants were informed orally of the purpose and nature of the study and its potential benefits. Because of the low levels of literacy, verbal consent was requested. As part of the consent procedure, the participants were informed that the data collected would be held in strict confidence. To ensure that the participant was aware that the survey included questions on highly-personal and sensitive topics, the interviewer forewarned the participant that some topics would be difficult to talk about. It was made clear to the woman that participation in the study was voluntary, and even if she agreed to participate in the study, she would be free to terminate the interview at any point and to skip any questions that she did not wish to respond to.

The following special measures were adopted to ensure that the study did not jeopardize the safety of the interviewees or the interviewers:

The place of interview was chosen according to the convenience of the study participants. The interviews were carried out in private, and only very young children, aged less than two years, were permitted to be present. Interviewers were trained to terminate or change the sensitive topic for dealing with interruptions. The training included a number of role-play exercises simulating different situations that may arise in the field. Each data collector carried a dummy questionnaire which excluded the sensitive questions. They were for use in case people outside the study insisted on reading the questionnaire,

The principle of doing no harm and respecting a person's decisions and choices was followed. The data collectors were trained to ask questions sensitively, in a supportive and non-judgemental manner. The importance of confidentiality was emphasized in the training. The questionnaire, tapes, and transcripts did not include any real names or addresses. Only the researchers had access to the data and used these exclusively for the purpose of research. The ethical review committees of ICDDR,B and Uppsala University approved the study.

\section{RESULTS}

\section{Background characteristics of women surveyed}

Background characteristics of the 372 abused women surveyed for programme-evaluation purpose are presented in Table 2. About 35\% of the women in the sample were aged 30 years or more while $12 \%$ were aged less than 20 years. About $41 \%$ had no education, and only $1 \%$ had post-secondary level of education. About 29\% came from the poor, $30 \%$ from below middle class, $22 \%$ from middle class, and the remaining from upper-middle class and the rich. About $15 \%$ had been exposed to physical, $36 \%$ to sexual, and $65 \%$ to emotional violence in their lifetime. The median SRQ score for all the pregnant women included the MINIMat study was 5. In this study sample, the score was 8 for ever emotionally-abused women, 7 for ever physicallyabused women, and 7 for ever sexually-abused women. About $28 \%$ of the study women reported suicidal ideation during the last four weeks.

\begin{tabular}{|c|c|}
\hline Characteristic of surveyed woman & Percentage \\
\hline \multicolumn{2}{|l|}{ Age (years) } \\
\hline$<20$ & 11.9 \\
\hline $20-24$ & 23.7 \\
\hline $25-29$ & 29.1 \\
\hline $30+$ & 35.3 \\
\hline \multicolumn{2}{|l|}{ Education in completed year } \\
\hline No & 40.8 \\
\hline Primary & 28.2 \\
\hline Secondary & 30.3 \\
\hline Post-secondary & 0.8 \\
\hline \multicolumn{2}{|l|}{ Socioeconomic status* } \\
\hline Poor & 29.0 \\
\hline Below middle class & 29.5 \\
\hline Middle class & 21.7 \\
\hline Upper-middle class & 9.4 \\
\hline Rich & 10.5 \\
\hline Exposed to lifetime physical violence & 15.3 \\
\hline Exposed to lifetime sexual violence & 36.0 \\
\hline \multicolumn{2}{|l|}{$\begin{array}{l}\text { Median mental stress score by expo- } \\
\text { sure to violence } \dagger\end{array}$} \\
\hline No violence based on larger dataset & 5 \\
\hline Emotional violence & 8 \\
\hline Physical violence & 7 \\
\hline Sexual violence & 7 \\
\hline Suicidal ideation & 28 \\
\hline \multicolumn{2}{|c|}{$\begin{array}{l}\text { *Socioeconomic status defined by the wealth } \\
\text { index based on principal component analysis } \\
\text { of assets owned by households; } \dagger \text { Distress score } \\
\text { was calculated based on responses to the self- } \\
\text { reported questionnaire-20 used in screening } \\
\text { for mental distress }\end{array}$} \\
\hline
\end{tabular}




\section{Time-related aspects of session}

Two issues may impact results and satisfaction of the participants with duration of session. First, people in rural Bangladesh usually do not measure time in terms of hours. Second, the lapse in time between the counselling session and the evaluation might have made recall an issue. To assess accuracy of the reporting of time, data collected on duration of the session was checked against some randomly-selected tapes from the sessions. Two categories of duration of the session were checked: (a) two hours or more and (b) 15 minutes or less. The results showed that no sessions went beyond an hour in the first category. However, duration of the sessions among women reporting 15 minutes or less actually ranged from 12 minutes to one hour. Therefore, the participants' reports of time-related aspects of the session must be seen as reflection of their perception rather than actual time. Although not accurate, they are assumed to indicate how the time-related aspects of the session were assessed by the women. This is why we considered it important to report how duration of session was perceived by women.

Table 3 shows that about 16\% of the women considered the scheduled time for the session inappropriate, 71\% thought it was okay, and 13\% considered it very convenient. The mean reported waiting-time was 48 minutes with the minimum waiting-time being zero and the maximum three hours. As reported by the women, about $16 \%$ had to wait more than an hour for the session while $52 \%$ had to wait half an hour or less.

About 55\% of the women were happy about the waiting-time, about 38\% were unhappy. About $58 \%$ of those who felt bad and 50\% of those who felt very bad about the waiting-time reported waiting more than one hour.
Shamima said,

Was not I takto (annoyed), while I was kept sitting and waiting? Afa (meaning elder sister used to refer to the paramedic) repeatedly made phone calls, and she was going out of the room. Would not this make me annoyed? ... The child was crying. I would have left her behind but I come from a nuclear family. The other children (who she left home) were small. I was worried whether they would fall in the water. [Age 38 years, grade 2 , non-poor, victim of physical violence, three children]

Data of in-depth interviews showed that women were unhappy about perceived long waiting-times mainly for the following reasons: (a) children, who accompanied them, kept crying and annoying them; (b) they had left children and their house in someone else's charge; (c) the paramedics seemed to keep them waiting until it was convenient for them to call the women in. The paramedics seemed to work leisurely and seemingly wasted time gossiping, chatting over phone, going here and there; (d) the sitting arrangement was not comfortable. It was hot, and there was no fan; and (e) snacks offered were not adequate.

Interestingly, $22 \%$ of those who felt bad and $2 \%$ of those who felt very bad about it waited for less than 30 minutes. On the other hand, 17\% of those who felt good and $8 \%$ of those who felt very good about the waiting-time waited for more than one hour. In-depth interview data give us a glimpse of how some women who had a long waiting-time could justify it. For example, Jamila, who reported waiting two and a half hours, tried to rationalize it as follows:

How would I feel [about the waiting-time]?

\begin{tabular}{|c|c|c|c|}
\hline Time related aspect & Timing of session & Waiting-time & Duration of session \\
\hline \multicolumn{4}{|c|}{ Opinion regarding timing of session } \\
\hline Very convenient & 13.2 & & \\
\hline Convenient & 70.7 & & \\
\hline Not convenient & 16.1 & & \\
\hline Not at all convenient & - & & \\
\hline \multicolumn{4}{|c|}{$\begin{array}{l}\text { How she felt about waiting-time and } \\
\text { duration of session }\end{array}$} \\
\hline Very bad & & 4.6 & 0.5 \\
\hline Bad & & 33.3 & 3.2 \\
\hline Nothing & & 7.5 & - \\
\hline Happy & & 50.3 & 68.8 \\
\hline Very happy & & 4.3 & 27.4 \\
\hline
\end{tabular}


What if I have problems waiting? This [i.e. reducing the waiting-time] is not so easy [for the paramedics]. They (i.e. the paramedics) have to folow the serial number. They are admitting people to the room one by one. It would always be this late if you go somewhere. ... Why would I get annoyed? [Age 32 years, no education, middle-class, victim of emotional violence]

The reported duration of each session, on average, was 54 minutes and ranged from 10 minutes to two hours and 25 minutes. Overall, the reported duration of the session was one hour or more for $52 \%$ of the women while it was half an hour or less for $38 \%$ of the women. Interestingly, the desired duration of the session was very close to the reported duration on average (58 minutes). About $61 \%$ of the women felt that the duration should be one hour or more while 30\% thought that it should be half an hour or less.

Ruma, a woman interviewed in-depth, appreciated the session extending to 30 minutes. She had the following interaction with the interviewer:

Interviewer: Was that half an hour adequate for you?...

Informant: It was all right. Could not be any better. ...

I could say everything I wanted.

[Age 19 years, grade 6, non-poor, victim of physical violence]

Although the length of the session was 90 minutes, Shahana was not annoyed as she was warned by the paramedic that the session might take a long time beforehand. She said,

No, it did not get late. When she called me in, she informed me how long the session might continue. She informed me beforehand. ... No. I was not annoyed. [Age 24 years, grade 8, nonpoor, victim of emotional violence]

There were also some women who were either partially or completely unhappy with the length of the session. Two of the 23 women who talked about duration of the session during the in-depth interview did not feel good about the session and felt irritated about spending a long time at the clinic. Shila was one of them. She said:

I was takto (irritated/annoyed). ... I was annoyed that I left my child in the corridor. They took me to another room. ... The child was crying.
She (paramedic) told me, "No problem. We gave him food, and he is now playing. I gave him toys as well. So, there is no problem. You just talk." I told her, "Get this over quickly. I am getting annoyed worrying about the child. [Age 29 years, no education, poor, victim of physical and sexual violence]

The total perceived time spent for availing of the session was not at all convenient for Latifa. Her statement shows that being away from the home for attending a clinic session might increase the risk of abuse by her husband. She was apprehensive of her husband getting aggressive and calling her names and hitting her. However, she did not tell the paramedic about her problems. Latifa put it as follows:

She talked for a long time. I wanted to come home. I knew his father (her husband) would mukh larhbo (scold me). He would kilaibo (punch me) and parhaibo (tread on) me. He would call me names. He would call me chodani shali (fucker) and demand of me "why did you stay at the clinic for such a long time. [Age 40 years, no education, poor, victim of physical and sexual violence]

Client satisfaction with privacy and confidentiality during counselling session

Table 4 illustrates how privacy and confidentiality were evaluated by the women. About 38\% of them had concerns regarding privacy before the session. The survey data showed that privacy was wellmaintained. Nobody else was present during the session, except for cases where the supervisor of the paramedic or a child of the woman not older than two years was present. In $95 \%$ of the cases, the door

\begin{tabular}{|c|c|}
\hline Aspect of privacy & Percentage \\
\hline \multicolumn{2}{|l|}{ Door was closed } \\
\hline Yes & 94.9 \\
\hline No & 5.1 \\
\hline \multicolumn{2}{|c|}{$\begin{array}{l}\text { Anybody present beside the super- } \\
\text { visor and a child aged }<2 \text { years? }\end{array}$} \\
\hline Yes & 0.0 \\
\hline No & 100.0 \\
\hline \multicolumn{2}{|c|}{ Attempt at keeping privacy } \\
\hline Very good & 30.1 \\
\hline Good & 61.8 \\
\hline So so & 0.8 \\
\hline Not good & 6.7 \\
\hline Very bad & 0.5 \\
\hline
\end{tabular}


was closed. About $92 \%$ of the women rated efforts at maintaining privacy as good or very good.

High appreciation of privacy maintained is illustrated in the following quote from an in-depth interviewee:

Interviewer: What did you appreciate most about going there, waiting, and talking?

Informant: [I liked most] That we talked in a sepa-rate room. This is what I liked. I liked that there was nobody else with us. So, we talked in private. This was a discussion of private matters, and nobody heard it. [Shahana, age 24 years, grade 8 , non-poor, victim of sexual violence]

Interestingly, $52 \%$ of the women reported they were not being at all concerned about confidentiality of the session. About $7 \%$ of the women were very much, $11 \%$ somewhat, and $26 \%$ moderately concerned about confidentiality. All of those who were concerned regarding confidentiality were afraid that the paramedics would tell others what was discussed. Qualitative data provide information on the types and sources of concerns regarding confidentiality. Thus, Julekha, who highly appreciated the session, shared her concerns regarding confidentiality. She said:

I liked the session very much. ... [After the session] my heart felt light. I felt that way because afa (paramedic in this instance) guaranteed that nobody else would get to know [my story]. If I ever get to understand or come to know that afa told my story to somebody else, I will feel ashamed and question myself for ever telling her [my story]. The pain I already carry is enough for me. Why would I invite additional suffering? I am bearing all the pain for the sake of protecting my attoshomman (prestige). [Age 36 years, grade 12 , non-poor, victim of severe physical and sexual violence]

Choitali said:

I was scared that there would be trouble in the family because of the disclosure. I thought about this and I was afraid. I used to argue with myself, "How can afa harm me using the information she got from me?" There are people who can create kanjala (trouble) in a family by saying things. ... I thought let me see what afa does. Now my child [who was born several months before the session] is almost four and nothing [no breach of confidentiality] has happened yet. Now, I am afraid no more. [Age 30 years, no education, poor, victim of physical and sexual violence]

Boishakhi was apprehensive of marriage breakdown if any information leaked. She said:

I was a bit scared. ... What if people get to know [that she shared her story]? If so, my marriage would be ruined. ... I was troubled a lot. I was troubled to the full extent. Even four-five days after the session, I was still telling myself, "what if my husband gets to know? My life would be ruined." I suffered so much! I suffered for about a week. ... At that time I could not share this with anyone else and I felt disturbed, totally disturbed. [Age 43 years, no education, non-poor, victim of physical and sexual violence]

\section{Evaluation of performance of paramedics as counsellors}

About $98 \%$ of the women reported that the paramedics conducted the session very well or well (Table 5). Everybody without exception reported that the paramedic treated her very well or well and listened to her attentively or very attentively. All the study participants held that behaviour of the paramedics was good enough and does not require any improvement.

Twenty-eight women interviewed in-depth were asked about the attitude and behaviour of the paramedics during the session. All of them appreciated the attitude and behaviour of the paramedics. Sixteen of them highly appreciated behaviour of the paramedics. For example, Parvin, a victim of severe physical and sexual violence, said:

I was very satisfied (shontushto hoisi). Other counselling clients comment on various aspects of behaviour of the paramedics, such as tone, body-language, language, etc.

She talked very nicely in a sweet voice. [Nazma, age 32 years, grade 8 , non-poor, victim of sexual violence]

She used a very bhodro bhasha (polished language), which I liked a lot. [Shelly, age 29 years, grade 5, non-poor, victim of physical violence]

The way she (the paramedic) talked was satisfying. You cannot attain any tripti (satisfaction) talking to many people. They would either talk angrily or say many improper things or would tuchchho (belittle) you. No, there was nothing like that in her (the paramedic's) manners that could be disliked. ... She always talks to me with a smiling face. [Shiuly, age 30 years, grade 


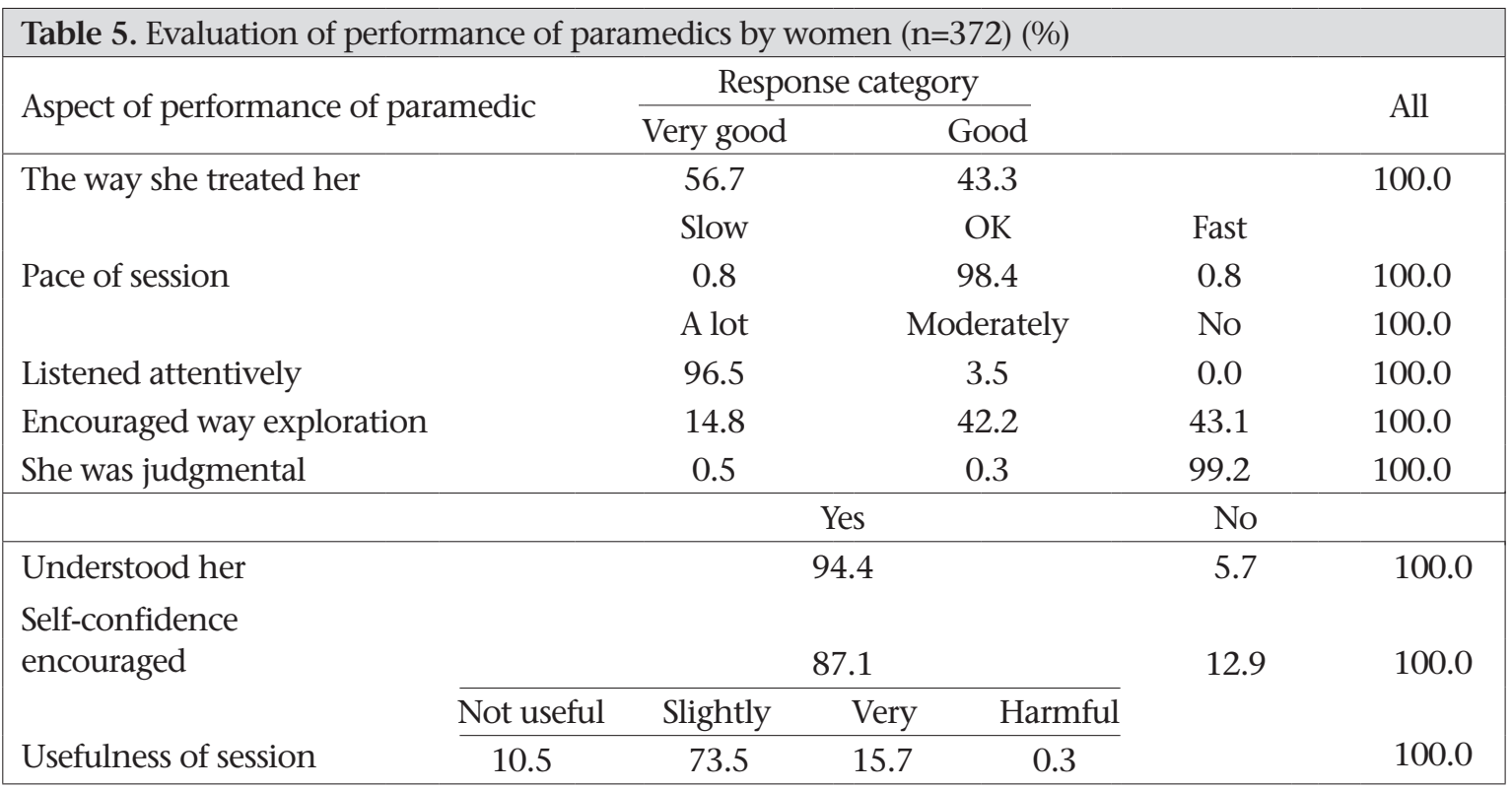

9, non-poor, victim of physical and sexual violence]

When women interviewed in-depth were asked whether the paramedics have treated them equally or looked down upon them, all the women appreciated equal treatment of the paramedics towards them.

She did not talk to me the way rich people usually talk to the poor. She treated me like a sister. She did not use any bad language. She was not conceited. She is a good person. [Asmani, age 27 years, grade 5, non-poor, victim of sexual violence]

I liked [how she treated me]. She is a doctor (...). Her position is much higher than mine. Thanks go to her for treating us equally and having for us the same sitting arrangement as her own. [Rahela, age 36 years, grade 3 , non-poor, victim of physical and sexual violence]

She showed that she cares a lot [for me]. She did not ignore me because she is a doctor. I am not lying. She is a doctor and I am an illiterate woman. Whatever she did she did it nicely and with a lot of care. [Sayema, age 27 years, no education, non-poor, victim of physical violence]

About $98 \%$ of the women considered the pace of the session appropriate, which is in line with the findings from the qualitative data.

About $99 \%$ of the women reported that, during the session, the paramedic had a non-judgemental attitude. About $94 \%$ felt that the paramedic under- stood her very well while the remaining women thought that she understood them more or less well. The paramedics encouraged about $57 \%$ of the women to explore a way out of the situation.

\section{Overall reaction to session}

To a directly-asked question whether the paramedic encouraged her to be self-confident, about $87 \%$ of the surveyed women answered in the positive. About $23 \%$ of the women who were encouraged to explore a way out of their current situation in terms of violence considered this discussion futile while $52 \%$ reported getting the idea that there might be some solution to her problem. Overall, $74 \%$ of the women reported that the session was useful a bit, and $16 \%$ reported that it was very useful. When asked in what way they thought the session was useful, $85 \%$ of the women who considered it useful said that it was so as it made them feel ' $h a l k a$ ' (light). About $22 \%$ of the women said that it was useful as it helped them understand violence against them was not their fault. The paramedic's depth of understanding and her empathy were mentioned as being considered useful by $19 \%$ of the women. About $8 \%$ of these women said that they found a new source of help, and 6\% reported that they found a new way of dealing with violence. About $3 \%$ were happy that ICDDR,B was attaching importance to this issue.

About $11 \%$ of the women interviewed did not consider the session useful. One woman said that the session was harmful as violence by husband increased due to disclosure of violence at this session. She commented that her husband interrogated her 
after the session and made her reveal what was discussed at the session.

The positive reactions were expressed as follows:

I liked it. ... I felt good talking, and afa listened to me, which helped me overcome my pain. ... I don't quite have people who I could open my heart to. ... I found such a person and I talked, which made me feel great. ... My heart felt light, and I had this good feeling even after I returned home. [Ruma, age 19 years, grade 6, non-poor, victim of physical violence]

I was monmora (depressed). I felt a little better after talking to her. ... Being able to talk to somebody lightens your heart. [Nazma, age 32 years, grade 8 , non-poor, victim of sexual violence]

Rahela elaborating why she had the same kind of feeling said:

I liked that she asked me questions-questions that nobody asks and nobody listens to so at- tentively. [Rahela, age 36 years, grade 3, nonpoor, victim of physical and sexual violence]

One of the recognized indicators of appreciation for service is the willingness to uptake the service again. As it was mentioned above that only nine women came for a second session. In response to the question why the others did not come for a second sessions, $53 \%$ of the women said that they did not need it. It is not clear from this response whether they did not need another session or whether they could not justify attending subsequent sessions. If we consider the proportion of women who said that the first session was useful, it seems that at least a proportion of the women who said that they did not need it must have referred to a second session. Among the women who did not come for a second session but did not say that it was not necessary, 50\% did not realize that a second session was available to them; $27 \%$ had not time to come for a second session; 11\% could not obtain permission or had family problems that did not allow them to come; and 5\% were either sick or upset.

\begin{tabular}{|c|c|c|}
\hline Independent variable & Odds ratios & $\begin{array}{c}\text { 95\% confidence } \\
\text { interval }\end{array}$ \\
\hline \multicolumn{3}{|l|}{ Age (year) } \\
\hline $20-24$ & 0.389 & 0.094-1.609 \\
\hline $25-29$ & 0.897 & $0.367-2.193$ \\
\hline $30+$ & 0.643 & $0.276-1.501$ \\
\hline \multicolumn{3}{|l|}{ Education } \\
\hline Primary & 0.145 & $0.007-3.018$ \\
\hline Secondary & 0.252 & $0.012-5.240$ \\
\hline Post-secondary & 0.263 & $0.013-5.208$ \\
\hline \multicolumn{3}{|l|}{ Wealth quintiles } \\
\hline Quintile & 1.072 & $0.294-3.911$ \\
\hline Quintile III & 0.711 & $0.207-2.436$ \\
\hline Quintile IV & 0.726 & $0.196-2.686$ \\
\hline Quintile V & 0.865 & $0.209-3.578$ \\
\hline Maintenance of privacy rated very good, Yes-No & 1.291 & $0.646-2.580$ \\
\hline Encouraged a lot to explore a way out, Yes-No & 7.670 & $3.648-16.126$ \\
\hline Discussion topic was considered very important, Yes-No & 2.396 & $1.200-4.782$ \\
\hline Encouraged to be self-confidence, Yes-No & 3.991 & $0.508-31.336$ \\
\hline Exposure to lifetime physical abuse by husband, Yes-No & 0.660 & $0.262-1.663$ \\
\hline Exposure to lifetime sexual abuse by husband, Yes-No & 1.102 & $0.523-2.321$ \\
\hline Constant & 0.178 & \\
\hline Ref=Reference & & \\
\hline
\end{tabular}




\section{Determinants of considering the session useful}

Logistic regression analysis was performed to explore the characteristics of women who found the session to be useful and to understand which features of the session were associated with usefulness. Considering the potential over-reporting of positive reaction to the session, we treated a dummy variable denoting the session either as very useful or not as the dependent variable. The independent variables included age, education of the woman and wealth index of her household, whether she considered the topic of discussion very important, whether attempt at maintaining privacy by the paramedic was highly appreciated, whether she was encouraged to be self-confident and to explore a way out of the situation, and her exposure to physical and sexual violence by husband (Table 6). The results showed that the women who considered the discussion topic very important were two times more likely to rate the session as very useful. Also, women who were strongly encouraged to explore a way out of violence were almost seven times more likely to consider the session very useful.

\section{DISCUSSION}

It is clear from the findings of the study that the sample consisting of abused women experienced higher levels of mental stress compared to a sample representing a mixture of non-abused and abused women. Also, a large proportion of these women had suicidal ideation. This highlights the need for mental health counselling service for these women. Most women were positive towards different aspects of the counselling session. The overwhelming majority of the women considered that the timing of the session was good or very good. The average duration of the session was close to the desired duration. Although most women were fine with the waiting-time, some women were unhappy about it. They had competing demands on their time due to childcare and household responsibilities and were concerned about an abusive husband. Some of them told the paramedics about these problems, and some did not. Interventions such as this need to be more sensitive to such issues and try to resolve them.

The paramedics conducted the sessions in private. Most women were confident about confidentiality. Some women who were concerned about confidentiality were later convinced that the concern was not justified.

Women were particularly positive about the perfor- mance of the paramedics. Most rated their performance in conducting the session as good or very good. Every participant felt that the paramedics treated her very well. According to the women, the paramedic listened to them very carefully. Most believed that the paramedics understood what they told them and considered that the paramedics had a non-judgemental attitude.

The paramedics encouraged the majority of women to be self-confident and encouraged more than half of the women to explore a way out of the violent situation. There is evidence in the literature to the effect that short-term counselling (four sessions at best) has reduced distress levels (33). However, these findings still hold surprising given the number of sessions the women had in this case. If the reports were not biased, enhanced selfconfidence might result in better coping skills of these women. The majority of the women found the session useful mostly because it offered them some relief to talk about their negative experiences. Women who considered discussion of violence very important were more likely to find the session very useful.

This is not surprising in light of the fact that the majority of abused women in Bangladesh do not talk about their experience but it is well-known that inhibiting or holding back one's thoughts, feelings, and behaviours is associated with long-term stress and disease (34). Actively confronting upsetting experiences - through writing or talking - is hypothesized to reduce the negative effects of inhibition, such as short-term autonomic activity (35-36) and long-term stress-related disease (37), by allowing individuals assimilate and reframe the negative experience (38-40).

This study also indicates that increasing efforts in exploring a way out of the violence might help make the session more useful to the women, and further intervention needs to take this into account.

It is important to note that these findings suggest that the first session was convenient for most women. The ethical guidelines were carefully followed in implementing the intervention. The session seemed to have offered most women some hope and relief. It must be recognized that the effects of the session as reported by the women were small but significant, particularly in light of the fact that most participants attended only one session. The additional benefit of attending multiple sessions remains to be explored. 
Attention must be given to the fact that attending a session at the clinic was not convenient for a group of women, and some women suggested that this could even escalate violence. This study does not shed light on the barriers in accessing this service for women who did not come to any sessions. Thus, research needs to be undertaken for understanding what inhibits some women to access such services; other strategies for reaching out these women need to be developed; and working with men to create an enabling situation for women to access services needs to be considered.

The fact that most abused women did not come for a second session might be an indicator of how the session was assessed by the women. This is why the reasons for not coming for the second session need to be considered carefully. It seems from the data that there was a communication gap regarding the availability of service, which must be addressed in future programmes. There also was a lack of understanding of what more consecutive sessions can offer to them. Thus, it is imperative to explain to abused women what mental health counselling aims to achieve and the process through which it attempts to achieve this goal. Means of helping women to manage time and hold sessions at a more convenient time for some women need to be explored. Strategies must be developed for overcoming gatekeepers and reaching out to women who are too sick or upset to come to a session. Transport also seems to be an issue for some women and needs due attention.

Relatively high satisfaction of the abused women with different aspects of mental health counselling service seems reasonable in light of the literature on client satisfaction regarding the quality of healthcare in rural Bangaldesh (41). Literature indicates that communication skills of healthcare providers are valued highly by the clients (42). Service providers' behaviour, especially respect and politeness, is the most powerful predictor of client satisfaction. For the participants of this study, this aspect was much more important than the technical competence of the service provider. These findings might suffer from some biases due to several reasons. First, women may have very low expectations from the service providers. As the literature shows, only $49 \%$ of the women reported that a family-planning health worker was usually sympathetic to their needs, and only about $60 \%$ were appreciative of their needs for privacy (43). In such a context, active listening skills of the paramedics, their nonjudgemental, equal and empathetic treatment of the abused women might have contributed to an overtly-positive assessment to the service. Also, it was not known by these women what a standard mental health counselling session consists of. The ability to talk about such private and sensitive issues was highly appreciated by the majority and has possibly contributed to their satisfaction with the service. This is not very unusual with women having a high level of distress and inability to share problems with others. Even in Germany where mental health service is quite developed, mature patients with subthreshold depression expected their general practitioners (GPs) to listen to them rather than take specific actions towards symptom relief (44). This underlines the fact that mental health patients have a special need for active listening to their problems, which is a potential contributer to their satisfaction with the service.

Second, the long-term relationship between ICDDR,B and the community and between the women and the paramedics who have been working in these communities for years are potential factors that might prompt the women to portray a positive picture of the service.

Measuring patient-reported outcomes and behaviours as close to the targeted exposure as possible has been recommended (45-47) due to several reasons. The main reasons are that long-term memory of past experiences does not fully decode details in unbiased ways (48); although recall of memories can produce believable and reasonable results, the results may or may not represent an accurate account of the target situation (49). Delayed assessment was found to overestimate the overall positive performance when compared with immediate assessment by exit cards (50).

So, an additional limitation of this study is that the evaluation was carried out one to two years after the women attended the counselling session, which might have contributed to an over-estimation of positive results.

Evaluations of the time-related aspects were probably not accurate, not only due to recall issues but also because rural women do not usually refer to time in terms of hours and mintues.

Despite possibilities of some biases in the results, the overwhelmingly-positive feedback from the women in both quantitative and qualitative exploration indicates that the session had some positive impact. In a context where $66 \%$ of the women never talk about their experience of violence (19), 
women are generally subordinated and lack selfconfidence, and professional mental health counselling services are absent, this initiative of training village-based paramedics in counselling for women exposed to violence looks sufficiently promising to warrant further testing. Further testing is needed for exploring how tangible is the achievement demonstrated here and what impact would it ultimately have on coping of women with violence. It should be noted that ICDDR,B's paramedics are more qualified than the national health workforce functioning at the village level. Thus, further research is also needed to explore the outcomes of implementing such services using the national health workforce.

It is well-recognized that multiple factors at different levels (e.g. family, community, society) contribute to violence against women. Thus, counselling targeted towards abused women only without taking greater community and societal issues into account is bound to have limitations $(20,22)$. Nevertheless, counselling of victims of violence against women offers an important step in managing this pervasive public health issue. This study offers some policyrelevant insights, which could be useful in initiating services for the abused women, suggesting that even in the context of an absence of professional counsellors in the country, trained paramedics can serve as the first-line support in mental healthcare for women suffering mental and physical ill-health relating to violence against women.

\section{ACKNOWLEDGEMENTS}

The present study is a part of MINIMat study. The MINIMat research study was funded by United Nations Children's Fund (UNICEF), Swedish International Development Cooperation Agency (SIDA), UK Medical Research Council, Swedish Research Council, Department for International Development (DFID)-UK, Global Health, Research FundJapan, Child Health and Nutrition Research Initiative (CHNRI), Uppsala University, United States Agency for Internatioal Development (USAID), and ICDDR,B. The mental health counselling component of the study and its evaluation were fully funded by Swedish International Development Cooperation Agency (SIDA) abd Department of Research Cooperation (SAREC) through International Maternal and Child Health, Uppsala University, Uppsala, Sweden. ICDDR,B also gratefully acknowledges the following donors which provide unrestricted support to the Centre's research efforts: Australian Agency for International Development (AusAID), Government of the People's Republic of Bangladesh, Canadian International Development
Agency (CIDA), Embassy of the Kingdom of the Netherlands (EKN), Swedish International Development Cooperation Agency (SIDA), Swiss Agency for Development and Cooperation (SDC), and Department for International Development (DFID), UK.

\section{REFERENCES}

1. Counts DA, Brown J, Campbell J. Sanctions and sanctuary: cultural perspectives on the beating of wives. Boulder, CO: Westview Press, 1992. 268 p.

2. Naved RT, Azim S, Bhuiya A, Persson LA. Physical violence by husbands: magnitude, disclosure and help seeking behavior of women in Bangladesh. Soc Sci Med 2006;62:2917-29.

3. García-Moreno C, Jansen HAFM, Ellsberg M, Heise L, Watts C. WHO multi-country study on women's health and domestic violence against women: initial results on prevalence, health outcomes and women's responses. Geneva: World Health Organization, 2005. $206 \mathrm{p}$.

4. Ratner PA. The incidence of wife abuse and mental health status in abused wives in Edmonton, Alberta. Canadian J Public Health 1993;84:246-9.

5. McCauley J, Kern DE, Kolodner K, Dill L, Schroeder AF, DeChant HK et al. The "battering syndrome" prevalence and clinical characteristics of domestic violence in primary care internal medicine practices. Ann Intern Med 1995;123:737-46.

6. Golding JM. Intimate partner violence as a risk factor for mental disorders: a meta-analysis. J Fam Violence 1999;14:99-132.

7. Cascardi M, O'Leary KD, Schlee KA. Co-occurrence and correlates of posttraumatice stress disorder and major depression in physically abused women. J Fam Violence 1999;14:227-50.

8. Campbell JC, Kub J, Belknap RA, Templin T. Predictors of depression in battered women. Violence Against Women 1997;3:271-93.

9. Campbell R, Sullivan CM, Davidson WS. Women who use domestic violence shelters: changes in depression over time. Psych Women Q 1995;19:237-55.

10. Campbell JC, Soeken K. Women's responses to battering over time: an analysis of change. J Interpers Violence 1999;14:21-40.

11. Silva C, McFarlane J, Soeken K, Parker B, Reel S. Symptoms of posttraumatic stress disorder in abused women in a primary care setting. J Women's Health 1997;6:543-52.

12. Ellsberg M, Caldera T, Herrera A, Winkvist A, Kullgren G. Domestic violence and emotional distress among Nicaraguan women: results from a population-based study. Am Psychol 1999;54:30-6. 
13. Fikree FF, Bhatti LI. Domestic violence and health of Pakistani women. Internat. J Gynaecol Obstet 1999;65:195-201.

14. Naved RT, Akhtar N. Spousal violence against women and suicidal ideation in Bangladesh. Women's Health Issues 2008;18:442-52.

15. Bennett L, Riger S, Schewe P, Howard A, Wasco S. Effectiveness of hotline, advocacy, counseling, and shelter services for victims of domestic violence: a statewide evaluation. I Interpersonal Violence 2004;19:815-29.

16. Cox JW, Stoltenberg CD. Evaluation of a treatment program for battered wives. J Family Violence 1991;6:395-413.

17. Howard A, Riger S, Campbell R, Wasco S. Counseling services for battered women: a comparison of outcomes for physical and sexual assault survivors. J Interpersonal Violence 2003;18:717-34.

18. Mancoske RJ, Standifer D, Cauley C. The effectiveness of brief counseling services for battered women. Res Soc Work Pract 1994;4:53-63.

19. Tutty LM. Post-shelter services: the efficacy of followup programs for abused women. Res Soc Work Pract 1996;6:425-44.

20. Tutty LM, Bidgood B, Rothery M. Support groups for battered women: research on their efficacy. J Family Violence 1993;8:325-43.

21. Straus MA, Hamby SL, Boney-McCoy S, Sugarman DB. The revised conflict tactics scale (CTS2): development and preliminary psychometric data. J Family Issues 1996;17:283-316.

22. Romano JL. Stress, coping, and well-being: applications of theory to practice. In: Welfel E, Ingersoll RE, editors. The mental health desk reference. New York, NY: Wiley, 2001:44-51.

23. Beck AA, Weishaar ME. Cognitive therapy. In: Corsini RJ, Wedding D, editors. Current psychotherapies. Itasca, IL: Peacock, 2000:241-72.

24. Ellis A. Rational emotive behavior therapy. In: Corsini RJ, Wedding D, editors. Current psychotherapies. Itasca, IL: Peacock, 2000:168-204.

25. Lazarus RS, Folkman S. Stress, appraisal, and coping. New York, NY: Springer, 1984. 456 p.

26. Sharma A. Visible women who have been abused of feminist therapeutic interventions with immigrant and racially healing the wounds of domestic abuse: improving the effectiveness. Violence Against Women 2001;7:1405.

27. Anderson H. Conversation, language and possibilities. New York, NY: Sprinter, 1997. 308 p.

28. White M, Epston F. Narrative means to therapeutic ends. New York, NY: Norton, 1989. 240 p.

29. Wyche KF, Rice JK. Feminist therapy: form dialogue to tenets. In: Worell J, Johnson NG, editors. Shaping the future of feminist psychology: education, research and practice. American Psychological Association, 1997:57-73.

30. Butler M. Guidelines for feminist therapy. In: Rosewater LB, Walker L, editors. Handbook of feminist therapy. New York, NY: Springer, 1985:2-38.

31. Yam, M. Wife abuse: strategies for a therapeutic response. Schol Inquiry Nur Pract 1995;9:147-58.

32. Anderson RT, Camacho FT, Balkrishnan R. Willing to wait?: the influence of patient wait time on satisfaction with primary Care. BMC Health Serv Res 2007;7:31.

33. Winzer R, Brucefors AB. Does a short-term intervention promote mental and general health among young adults? - an evaluation of counseling, BMC Public Health 2007; 7:319.

34. Pennebaker JW, Kiecolt-Glaser JK, Glaser R. Disclosure of traumas and immune function: health implications for psychotherapy. J Consult Clin Psychol 1988;56:239-45.

35. Fowles DC. The three arousal model: implications of Gray's two-factor theory for heart rate, electrodermal activity, and psychopathy. Psychophysiology 1980;17:87-104.

36. Gray J. Elements of a two-process theory of learning. New York, NY: Academic Press, 1975. 426 p.

37. Pennebaker JW, Susman JR. Disclosure of traumas and psychosomatic processes. Soc Sci Med 1988;26:32732.

38. Horowitz, MJ. Stress response syndromes: personality styles and interventions. New York, NY: Jacob Aronson Inc., 1976. $451 \mathrm{p}$.

39. Meichenbaum DH. Cognitive-behavior modification: an integrative approach. New York, NY: Plenum Press, 1977. 305 p.

40. Silver RL, Boon C, Stones MH. Searching for meaning in misfortune: making sense of incest. J Soc Issues 1983;39:81-102.

41. Aldana JM, Piechulek H, Al-Sabir A. Client satisfaction and quality of health care in rural Bangladesh. Bull World Health Organ 2001;79:512-7.

42. Andaleeb SS. Public and private hospitals in Bangladesh: service quality and predictors of hospital choice. Health Policy Plann 200;15:95-102.

43. Koenig MA, Hossain MB, Whittaker M. The influence of quality of care upon contraceptive use in rural Bangladesh. Stud Fam Plann 1997;28:278-89.

44. Backenstrass M, Joest K, Rosemann T, Szecsenyi J. The 
care of patients with subthreshold depression in primary care: is it all that bad? A qualitative study on the views of general practitioners and patients. $B M C$ Health Serv Res 2007;7:190.

45. Shiffman S, Gwaltney CJ, Balabanis MH, Liu KS, Paty JA, Kassel JD et al. Immediate antecedents of cigarette smoking: an analysis from ecological momentary assessment. J Abnorm Psychol 2002;111:531-45.

46. Janicki DL, Kamarck TW, Shiffman S, Gwaltney CJ. Application of ecological momentary assessment to the study of marital adjustment and social interactions during daily life. J Fam Psychol 2006;20:168-72.

47. Moskowitz DS, Young SN. Ecological momentary assessment: what it is and why it Is a method of the future in clinical psychopharmacology. J Psychiatry
Neurosci 2006;31:13-20.

48. Bradburn NM, Rips LJ, Shevell SK. Answering autobiographical questions: the impact of memory and inference on surveys. Science 1987;236:157-61.

49. Shiffman S, Hufford M, Hickcox M, Paty JA, Gnys M, Kassel JD. Remember that? A comparison of real-time versus retrospective recall of smoking lapses. J Consult Clin Psychol 1997;65:292-300.

50. Houston TK, Richman JS, Coley HL, Ray MN, Allison JJ, Gilbert GH et al.; DPBRN Collaborative Group. Does delayed measurement affect patient reports of provider performance? Implications for performance measurement of medical assistance with tobacco cessation: a dental PBRN study. BMC Health Services Res 2008;8:100. 